\title{
Review \\ Clinical review: Medication errors in critical care
}

\author{
Eric Moyen, Eric Camiré and Henry Thomas Stelfox
}

Department of Critical Care Medicine, University of Calgary, Foothills Medical Centre, EG23A, 1403-29 Street NW, Calgary, AB, Canada, T2N 2T9

Corresponding author: Henry Thomas Stelfox, tom.stelfox@calgaryhealthregion.ca

Published: 12 March 2008

This article is online at http://ccforum.com/content/12/2/208

(c) 2008 BioMed Central Ltd
Critical Care 2008, 12:208 (doi:10.1186/cc6813)

process an error occurs, the more likely it is to be intercepted [12]. Administration appears to be particularly vulnerable to error because of a paucity of system checks as most medications are administered by a single nurse [13]. Nurses and pharmacists intercept up to $70 \%$ of prescription errors [14]. Preparation errors occur when there is a difference between the ordered amount or concentration of a medication and what is actually prepared and administered. The industry standard for pharmaceutical preparations is a concentration difference of less than 10\% [15]. However, approximately two thirds of infusions prepared by nurses are outside industry-accepted standards and 6\% contain a greater than twofold concentration error [16]. Transcription errors are usually attributed to handwriting, abbreviation use, unit misinterpretation ('mg' for 'mcg'), and mistakes in reading.

\section{How are medication errors classified?}

James Reason developed a well-recognized system for human error classification based on observations from industries that have become highly reliable such as aviation and nuclear power [17]. He states that errors arise for two reasons: active failures and latent conditions.

Active failures are unsafe acts committed by people who are in direct contact with the patient. They take a variety of forms: slips, lapses, and mistakes (Table 1). Slips and lapses are skill-based behavior errors, when a routine behavior is misdirected or omitted. The person has the right idea but performs the wrong execution. For example, forgetting to restart an infusion of heparin postoperatively is a lapse. Restarting the heparin infusion but entering an incorrect infusion rate despite knowing the correct rate is a slip. Mistakes are knowledge-based errors (perception, judgment, inference, and interpretation) and occur due to incorrect thought processes or analyses. For example, prescribing heparin in a patient diagnosed with heparin-induced thrombocytopenia is a mistake. Situational factors (fatigue, drugs, alcohol, stress, and multiple activities) can divert attention and increase the risk of active failures.

$\mathrm{ADE}=$ adverse drug event; $\mathrm{CPOE}=$ computerized physician order entry; ICU = intensive care unit; $\mathrm{IOM}=$ Institute of Medicine. 
Table 1

\begin{tabular}{ll} 
Definitions & \\
\hline Medical error & $\begin{array}{l}\text { The failure of a planned action to be } \\
\text { completed as intended or the use of a wrong } \\
\text { plan to achieve an aim [2]. }\end{array}$ \\
Medication error & $\begin{array}{l}\text { Any error in the medication process, whether } \\
\text { there are adverse consequences or not [10]. }\end{array}$ \\
Adverse drug event & $\begin{array}{l}\text { Any injury related to the use of a drug [77]. } \\
\text { Not all adverse drug events are caused by } \\
\text { medical error, nor do all medication errors } \\
\text { result in an adverse drug event [26]. }\end{array}$ \\
Preventable adverse & $\begin{array}{l}\text { Harm that could be avoided through } \\
\text { reasonable planning or proper execution of an } \\
\text { action [6]. }\end{array}$ \\
Near miss & $\begin{array}{l}\text { The occurrence of an error that did not result } \\
\text { in harm [6]. }\end{array}$ \\
Slip & $\begin{array}{l}\text { A failure to execute an action due to a routine } \\
\text { behavior being misdirected [17]. }\end{array}$ \\
Lapse & $\begin{array}{l}\text { A failure to execute an action due to lapse in } \\
\text { memory and a routine behavior being omitted } \\
\text { [17]. } \\
\text { A knowledge-based error due to an incorrect }\end{array}$ \\
Error of commission & $\begin{array}{l}\text { thought process or analysis [17]. } \\
\text { Failure to perform an appropriate action [6]. } \\
\text { Performing an inappropriate action [6]. }\end{array}$ \\
\hline
\end{tabular}

Latent conditions are resident pathogens within the system. They can affect the rate at which employees execute active failures and the risks associated with active failures. Latent failures occur when individuals make decisions that have unintended consequences in the future [17]. Prevention requires an ongoing tenacious search and corrective actions once latent conditions are identified. For example, institutions that use staffing models that depend on providers to routinely perform clinical duties above and beyond their regular responsibilities paradoxically risk introducing time pressures, fatigue, and low morale into their work force.

Errors can alternatively be classified as errors of omission or errors of commission (Table 1). Errors of omission are defined as failure to perform an appropriate action [6]. On average, patients receive only half of the recommended care they should receive [18]. Errors of commission are defined as performing an inappropriate action [6]. Most studies in the patient safety literature focus on errors of commission such as wrong drug or wrong dose. Problems with effectiveness and access to drug therapy have been studied much less frequently [19].

\section{How common are medication errors?}

The reported incidence of medication errors varies widely between clinical settings and patient populations and between studies. Errors appear to occur in approximately 6\% of hospital medication use episodes [11]. Among critically ill adults, the rate of medication errors ranges from 1.2 to 947 errors per 1,000 patient ICU days with a median of 106 errors per 1,000 patient ICU days [20]. In children, 100 to 400 prescribing errors have been reported per 1,000 patients [21]. Several factors account for this large variation in reported medication errors. First, the definition of medication error, including both the numerator and denominator selected for rate calculations, is critical. For example, medication errors and adverse drug events (ADEs) are frequently reported as individual events, as a numerator, but with no denominator [6]. Furthermore, selecting an appropriate denominator that reflects exposure to risk can be difficult [6]. Should medication errors be reported per patient, patient day, medication day, or dose administered? Second, the process node (prescription, transcription, and so on) under investigation will influence incidence estimates [20]. Third, the method of reporting medication errors influences rate estimates $[22,23]$. Spontaneous reporting of medication errors may under-report events $[11,22]$. Review of the medical records is considered by many experts the benchmark for estimating the extent of errors and adverse events in hospitals but is dependent on accurate documentation [24]. Automation of medical record reviews with computers can be used to improve efficiency and allow for prospective reviews [22]. Direct patient monitoring may be the ultimate reference standard but is dependent on observer expertise and is very labor-intensive [25]. Fourth, the culture of individual ICUs, the number of ICUs participating in error reporting, and the technologies employed can significantly influence error reporting. Medication error trends over time using the same standardized measurement tools are more likely to provide valuable information than periodic cross-sectional surveys.

\section{What are the consequences of medication errors?}

Medication errors are an important cause of patient morbidity and mortality [9]. Although only $10 \%$ of medication errors result in an ADE, these errors have profound implications for patients, families, and health care providers $[13,26,27]$. The IOM report highlights that 44,000 to 98,000 patients die each year as a result of medical errors, a large portion of these being medication-related [2]. Approximately one fifth (19\%) of medication errors in the ICU are life-threatening and almost half $(42 \%)$ are of sufficient clinical importance to warrant additional life-sustaining treatments [28]. However, deaths are only the tip of the iceberg. The human and societal burden is even greater with many patients experiencing costly and prolonged hospital stays and some patients never fully recovering to their premorbid status $[29,30]$. Bates and colleagues [30] estimated that in American hospitals the annual cost of serious medication errors in 1995 was \$2.9 million per hospital and that a $17 \%$ decrease in incidence would result in $\$ 480,000$ savings per hospital. Finally, the psychological impact of errors should not be ignored [30]. Errors erode patient, family, and public confidence in health 
care organizations [31]. Memories of error can haunt providers for many years [32].

\section{What is unique about the ICU and medication errors?}

The ICU brings together high-risk patients and interventions in a complex environment (Table 2) [33]. The single strongest predictor of an ADE is patient illness severity [34]. Critically ill patients are prescribed twice as many medications as patients outside of the ICU [35]. Most medications in the ICU are administered as weight-based infusions. These infusions require mathematical calculations and frequently are based on estimated weights increasing the risk of error $[20,28]$. Multicentered studies by Ridley and colleagues [36] and Calabrese and colleagues [13] identified potassium chloride, heparin, magnesium sulphate, vasoactive drugs, sedatives, and analgesics as the medications with the greatest risk of error. Antibiotics frequently are empirically prescribed in the ICU and errors have potential implications both for individual patients and populations $[37,38]$. Patients are prescribed these medications in an environment that is stressful, complex, changing, under the stewardship of multiple providers, and frequently managing patients in crisis [20]. It is important to remember that critically ill patients have fewer defenses against adverse events than other patients do. They have limited ability to participate in their medical care and they lack the physiological reserve to tolerate additional injury. Moreover, they are reliant on sophisticated technologies and equipment to deliver essential care and yet relatively little is known about medical equipment failures and the associated safety risks. Finally, lack of continuity of care at discharge from the ICU is a well-known feature putting the patient at risk for errors and highlights the importance of communication with the future caregivers [39].

\section{How can we prevent medication errors?}

Improved medication safety can be accomplished by optimizing the safety of the medication process, eliminating situational risk factors, and providing strategies to both intercept errors and mitigate their consequences. Several interventions have been shown to decrease medical error in the ICU (Table 3).

The safest and most efficient means of improving patient safety is to improve the safety of the medication process. Strategies that have been shown to be successful include medication standardization [40,41], computerized physician order entry (CPOE) [42,43], bar code technology [44,45], computerized intravenous infusion devices [9], and medication reconciliation [46]. CPOE targets the prescription and transcription stages of the medication process. The technology permits clinicians to enter orders directly into a computer workstation that is linked to a hospital clinical information system [47]. The main advantages of these systems are that they can track allergies, recommend drug dosages, provide adjustments for patients with altered renal or hepatic
Table 2

Risk factors for medication errors in the intensive care unit

\begin{tabular}{ll}
\hline Factors & Specific risk factors \\
\hline Patient & Severity of illness \\
& Strongest predictor of ADE [25,34] \\
ICU patients more likely to experience ADE & than patients in other units [35] \\
& Extreme of ages \\
& Increased susceptibility to ADEs [2,78] \\
& Prolonged hospitalization \\
& Increased exposure and susceptibility to ADEs \\
& [2,78] \\
Sedation & \\
Patients unable to participate in care and \\
defend themselves against errors [9]
\end{tabular}

$A D E$, adverse drug event; ICU, intensive care unit.

function, and identify potential drug-drug interactions [11]. Major limitations for implementation include capital costs, provider willingness to adopt the technology, and worries about technical malfunctions and paradoxical increases in medication errors during implementation periods $[9,48]$. Two systematic reviews have documented that CPOE systems increase clinician adherence to guidelines and alerts, improve organizational efficiency, reduce costs, and even prevent medication errors, but there is limited evidence to support improved patient safety $[42,43]$. In this regard, CPOE technology highlights the important distinction between error and harm; errors are an important intermediate outcome, but preventing patient harm is the ultimate goal [49]. CPOE technology currently is not used in the majority of ICUs [50]. 
Table 3

\section{Sample strategies to prevent medication errors}

Optimize the medication process

1. Medication standardization

2. Computerized physician order entry and clinical decision support

3. Bar code technology

4. Computerized intravenous infusion devices

5. Medication reconciliation

Eliminate situational risk factors

1. Avoid excessive consecutive and cumulative working hours

2. Minimize interruptions and distractions

3. Trainee supervision and graduated responsibility

Oversight and error interception

1. Intensivist participation in ICU care

2. Adequate staffing

3. Pharmacist participation in ICU care

4. Incorporation of quality assurance into academic education

$\mathrm{ICU}$, intensive care unit.

Bar code technologies target the administration phase of the medication process. Used in conjunction with CPOE, bar code labels for the medication, the patient, and the provider administering the medication are scanned, reconciled, and documented electronically. This process helps ensure that the correct patient gets the correct dose of the correct drug by the correct route at the correct time [44]. Administration errors have been documented to be reduced by $60 \%$ [45]. Computerized intravenous infusion devices allow incorporation of CPOE and bar code technology for intravenous medications such that standardized concentrations, infusion rates, and dosing limits can be provided to help prevent intravenous medication errors [9].

Three quarters of patient medications are stopped on patient admission to the ICU [39,51]. Many of these medications are not restarted by the time of patient discharge from the ICU $(88 \%)$ or hospital $(30 \%)$ [39,51]. Medication reconciliation is a process that matches a patient's current hospital medication regimen against a patient's long-term medication regimen. A coordinated medication reconciliation program can prevent drug withdrawal and ensure that life-saving medications are continued or restarted as soon as appropriate [46].

Situational risk factors can divert providers' attention and increase the risk of active failures. These need to be minimized. For example, acute and chronic sleep deprivation among residents has been shown to increase the risk of error $[52,53]$. Therefore, it seems reasonable to establish clinical routines that balance the risk of provider fatigue against the risk of frequent patient sign-over [54]. Trainee supervision and graduated responsibility represent additional risk factors that need to be managed. Clinical inexperience can have a major impact on errors. First-year residents are five times more likely to make prescribing errors than those with more experience [55], as are residents at the start of new rotations [56]. Pharmacological knowledge is an independent predictor of medication errors by health care providers [11]. It is important to capture providers when they start in new environments, train them, and then provide graduated supervision as they develop experience [57]. Although efforts should be directed at targeting situational risk factors, it is important to note that most medication errors occur when individuals are working under what they perceive to be reasonably normal conditions and denying fatigue, stress, or distractions at the time of the error [35].

Physicians, nurses, and pharmacists are integral to medication oversight and error interception. Participation of an intensivist in patient care in the ICU has been reported to decrease medication errors from $22 \%$ to $70 \%$ [58], complications by $50 \%$ [59], ICU mortality, ICU length of stay, and hospital length of stay and to improve patient safety [60]. Pharmacists, similarly, have an important role to play in medication safety. First, all intravenous medications should be prepared within the pharmacy department by pharmacists using a standardized process and standardized medication concentrations. Second, participation of a pharmacist in clinical rounds improves patient safety by reducing preventable ADEs by $66 \%$ [61] while shortening patients' length of hospital stay [62,63], decreasing mortality [64], and decreasing medication expenditures $[65,66]$.

Nurses play a particularly important role in patient safety because they are the health care providers with whom patients are likely to spend the greatest amount of time. This has two important implications. One, decreasing nurse-topatient staffing ratios may be associated with an increased risk of medical errors $[67,68]$. Nurse-to-patient ratios of $1: 1$ or 1:2 appear to be safest in the ICU [69]. Second, nursing experience may have an important influence on patient safety. Experienced nurses are more likely to intercept errors compared with less experienced nurses [70].

\section{What can we learn from errors?}

Incompetent or irresponsible clinicians do not cause most adverse events. James Reason provides a compelling explanation of error using Swiss cheese as a model (Figure 1). In the real world, our defenses against adverse events, like slices of Swiss cheese, are imperfect. These holes continually open, close, and shift their locations. An adverse event occurs when the holes in many layers of defense momentarily line up [71]. Therefore, it is not surprising that models of quality improvement based on identifying and removing 'bad apple' clinicians have not been effective in improving the safety of health care [72]. 
Figure 1

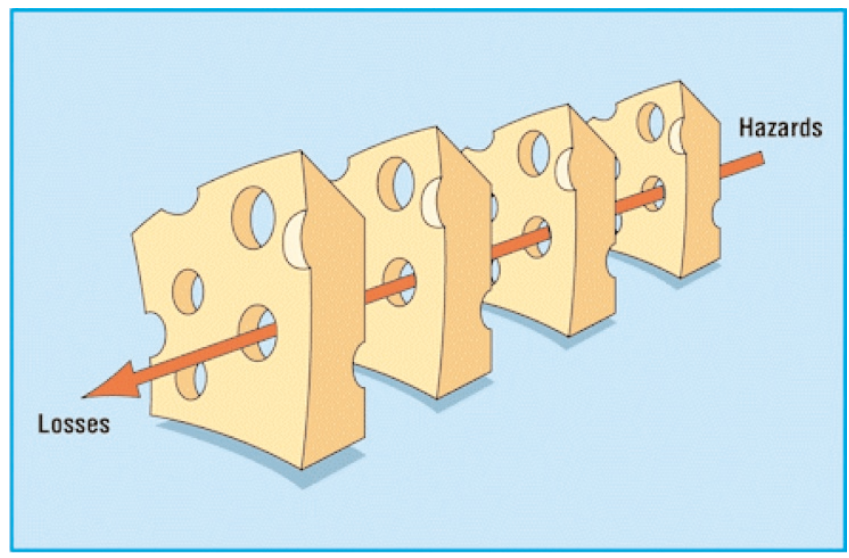

James Reason's Swiss cheese model of defenses. Reprinted from the $B M J$ [71] (copyright 2000) with permission from the BMJ Publishing Group Ltd.

Conversely, high-reliability organizations such as aircraft carriers, nuclear power plants, and air traffic controllers have markedly improved safety by standardizing practices and investing in safety training and research $[71,73]$. Three simple strategies to change medicine's approach to medication errors have been proposed [74]: (a) recognize that current approaches for preventing medication errors are inadequate; (b) improve the error-reporting system, avoid punishment, and focus on identifying performance improvement opportunities; and (c) understand and enhance human performance within the medication use process.

We should focus on developing systems that view humans as fallible and assume that errors will occur, even in the best organizations. In this model, multiple barriers and safeguards can be developed to reduce the frequency of ADEs. Error reporting is an important component of this strategy because it reveals the active failures and latent conditions in the system [6]. Near misses are incidents that did not lead to harm but could have resulted in patient injury. Reporting these as well as adverse events offers several advantages over reporting only adverse events. These include greater event frequency for quantitative analysis, fewer reporting barriers partly owing to fewer liability concerns, and an opportunity to study recovery patterns [75]. Ideally, error reporting should be voluntary, anonymous, centralized to increase the pool of data, and designed to identify opportunities for performance improvement. However, error reporting alone will not improve patient safety but rather is the first step in a continuous quality improvement cycle [6]. In addition, error reporting has its limitations. Like any intervention, it can have unintended consequences such as creating incentives for gaming the health care system, particularly if penalties or rewards are directly or indirectly associated with reporting [76]. In addition, error reporting can be labor-intensive. For example, a 10-bed ICU could be anticipated to produce more than 6,200 error reports per year ( 1.7 errors per patient per day $\times 10$ beds $\times 365$ days). Reporting near misses would substantially increase the number of reports. Some systems such as the AIMS-ICU (Australian Incident Monitoring Study in Intensive Care) and the ICUSRS (Intensive Care Unit Safety Reporting System) have been developed with the goal of balancing the strengths and limitations of error reporting [72].

\section{Conclusion}

Patient safety is an important health care issue because of the consequences of iatrogenic injuries. Medication errors in critical care are frequent, serious, and predictable. Human factor research in nonmedical settings suggests that demanding greater vigilance from providers of medical care may not result in meaningful safety improvement. Instead, the approach of identifying failures and redesigning faulty systems appears to be a more promising way to reduce human error.

\section{Competing interests}

The authors declare that they have no competing interests.

\section{Authors' contributions}

EC and EM performed the literature search and partially drafted and revised the manuscript. HTS designed the literature search strategy and partially drafted and revised the manuscript. All authors read and approved the final manuscript.

\section{Acknowledgments}

The authors thank Sharon Straus and Heather Jeppesen for their comments on an earlier draft of this manuscript.

\section{References}

1. Medical errors: the scope of the problem [http://www.ahrq.gov/ qual/errback.htm].

2. Kohn LT, Corrigan JM, Donaldson MS: To Err is Human: Building a Safer Health System. Washington: National Academy Press; 1999.

3. Stelfox HT, Palmisani S, Scurlock C, Orav EJ, Bates DW: The 'To Err is Human' report and the patient safety literature. Qual Saf Health Care 2006, 15:174-178.

4. Leape LL, Berwick DM: Five years after To Err Is Human: what have we learned? JAMA 2005, 293:2384-2390.

5. Donchin Y, Gopher D, Olin M, Badihi Y, Biesky M, Sprung CL, Pizov R, Cotev S: A look into the nature and causes of human errors in the intensive care unit. Crit Care Med 1995, 23:294300.

6. Pronovost PJ, Thompson DA, Holzmueller CG, Lubomski LH, Morlock LL: Defining and measuring patient safety. Crit Care Clin 2005, 21:1-19.

7. Rothschild JM, Landrigan CP, Cronin JW, Kaushal R, Lockley SW, Burdick E, Stone PH, Lilly CM, Katz JT, Czeisler CA, Bates DW: The Critical Care Safety Study: The incidence and nature of adverse events and serious medical errors in intensive care. Crit Care Med 2005, 33:1694-1700.

8. Pharmacy-nursing shared vision for safe medication use in hospitals: executive summary session. Am J Health Syst Pharm 2003, 60:1046-1052.

9. Hussain E, Kao E: Medication safety and transfusion errors in the ICU and beyond. Crit Care Clin 2005, 21:91-110.

10. Leape LL: Preventing adverse drug events. Am J Health Syst Pharm 1995, 52:379-382. 
11. Krahenbuhl-Melcher A, Schlienger R, Lampert $M$, Haschke M, Drewe J, Krahenbuhl S: Drug-related problems in hospitals: a review of the recent literature. Drug Safety 2007, 30:379-407.

12. Bates DW, Cullen DJ, Laird N, Petersen LA, Small SD, Servi D, Laffel G, Sweitzer BJ, Shea BF, Hallisey R: Incidence of adverse drug events and potential adverse drug events. Implications for prevention. ADE Prevention Study Group. JAMA 1995, 274:29-34

13. Calabrese AD, Erstad BL, Brandl K, Barletta JF, Kane SL, Sherman DS: Medication administration errors in adult patients in the ICU. Intensive Care Med 2001, 27:1592-1598.

14. Leape LL, Bates DW, Cullen DJ, Cooper J, Demonaco HJ, Gallivan T, Hallisey R, Ives J, Laird N, Laffel G, Nemeskal R, Petersen LA, Porter K, Servi D, Shea BF, Small SD, Sweitzer BJ, Thompson T, Vander Vliet M, for the ADE Prevention Study Group: Systems analysis of adverse drug events. ADE Prevention Study Group. JAMA 1995, 274:35-43.

15. The United States Pharmacopeial Convention: 1999. Rockville, MD: United States Pharmacopeia; 1999:1131-1132.

16. Parshuram CS, Ng GYT, Ho TKL, Klein J, Moore AM, Bohn D, Koren G: Discrepancies between ordered and delivered concentrations of opiate infusions in critical care. Crit Care Med 2003, 31:2483-2487.

17. Reason J: Human Error. Cambridge: Cambridge University Press; 1990.

18. McGlynn EA, Asch SM, Adams J, Keesey J, Hicks J, DeCristofaro A, Kerr EA: The quality of health care delivered to adults in the United States. N Engl J Med 2003, 348:2635-2645.

19. Kanjanarat $P$, Winterstein AG, Johns TE, Hatton RC, GonzalezRothi R, Segal R: Nature of preventable adverse drug events in hospitals: a literature review. Am J Health Syst Pharm 2003, 60:1750-1759.

20. Kane-Gill S, Weber RJ: Principles and practices of medication safety in the ICU. Crit Care Clin 2006, 22:273-290.

21. Miller MR, Robinson KA, Lubomski LH, Rinke ML, Pronovost PJ: Medication errors in paediatric care: a systematic review of epidemiology and an evaluation of evidence supporting reduction strategy recommendations. Qual Saf Health Care 2007, 16:116-126.

22. O'Neil AC, Petersen LA, Cook EF, Bates DW, Lee TH, Brennan TA: Physician reporting compared with medical-record review to identify adverse medical events. Ann Intern Med 1993, 119: 370-376.

23. Flynn EA, Barker KN, Pepper GA, Bates DW, Mikeal RL: Comparison of methods for detecting medication errors in 36 hospitals and skilled-nursing facilities. Am J Health Syst Pharm 2002, 59:436-446

24. Michel P, Quenon JL, de Sarasqueta AM, Scemama O: Comparison of three methods for estimating rates of adverse events and rates of preventable adverse events in acute care hospitals. BMJ 2004, 328:199.

25. Andrews LB, Stocking C, Krizek T, Gottlieb L, Krizek C, Vargish T, Siegler M: An alternative strategy for studying adverse events in medical care. Lancet 1997, 349:309-313.

26. Bates DW, Boyle DL, Vander Vliet MB, Schneider J, Leape L: Relationship between medication errors and adverse drug events. J Gen Intern Med 1995, 10:199-205.

27. Barker KN, Flynn EA, Pepper GA, Bates DW, Mikeal RL: Medication errors observed in $\mathbf{3 6}$ health care facilities. Arch Intern Med 2002, 162:1897-1903.

28. Tissot E, Cornette C, Demoly P, Jacquet M, Barale F, Capellier G: Medication errors at the administration stage in an intensive care unit. Intensive Care Med 1999, 25:353-359.

29. Classen DC, Pestotnik SL, Evans RS, Lloyd JF, Burke JP: Adverse drug events in hospitalized patients. Excess length of stay, extra costs, and attributable mortality. JAMA 1997, 277:301-306.

30. Bates DW, Leape LL, Cullen DJ, Laird N, Petersen LA, Teich JM, Burdick E, Hickey M, Kleefield S, Shea B, Vander Vliet M, Seger DL: Effect of computerized physician order entry and a team intervention on prevention of serious medication errors. JAMA 1998, 280:1311-1316.

31. Cohen H, Mandrack MM: Application of the $80 / 20$ rule in safeguarding the use of high-alert medications. Crit Care Nurs Clin North Am 2002, 14:369-374.

32. Christensen JF, Levinson W, Dunn PM: The heart of darkness: the impact of perceived mistakes on physicians. J Gen Intern Med 1992, 7:424-431.
33. Pronovost PJ, Weast B, Holzmueller CG, Rosenstein BJ, Kidwell RP, Haller KB, Feroli ER, Sexton JB, Rubin HR: Evaluation of the culture of safety: survey of clinicians and managers in an academic medical center. Qual Saf Health Care 2003, 12:405-410.

34. Giraud T, Dhainaut JF, Vaxelaire JF, Joseph T, Journois D, Bleichner G, Sollet JP, Chevret S, Monsallier JF: latrogenic complications in adult intensive care units: a prospective two-center study. Crit Care Med 1993, 21:40-51.

35. Cullen DJ, Sweitzer BJ, Bates DW, Burdick E, Edmondson A, Leape LL: Preventable adverse drug events in hospitalized patients: a comparative study of intensive care and general care units. Crit Care Med 1997, 25:1289-1297.

36. Ridley SA, Booth SA, Thompson CM, Clayton T, Eddleston J, Mackenzie S, Thomas T, Webb A, Wright D: Prescription errors in UK critical care units. Anaesthesia 2004, 59:1193-1200.

37. Kollef $\mathrm{MH}$, Sherman G, Ward S, Fraser VJ: Inadequate antimicrobial treatment of infections: a risk factor for hospital mortality among critically ill patients. Chest 1999, 115:462474.

38. Ibrahim EH, Sherman G, Ward S, Fraser VJ, Kollef MH: The influence of inadequate antimicrobial treatment of bloodstream infections on patient outcomes in the ICU setting. Chest 2000, 118:146-155.

39. Campbell AJ, Bloomfield R, Noble DW: An observational study of changes to long-term medication after admission to an intensive care unit. Anaesthesia 2006, 61:1087-1092.

40. Larsen GY, Parker HB, Cash J, O'Connell M, Grant MC: Standard drug concentrations and smart-pump technology reduce continuous-medication-infusion errors in pediatric patients. Pediatrics 2005, 116:e21-25.

41. Bullock J, Jordan D, Gawlinski A, Henneman EA: Standardizing IV infusion medication concentrations to reduce variability in medication errors. Crit Care Nurs Clin North Am 2006, 18:515521.

42. Shamliyan TA, Duval S, Du J, Kane RL: Just what the doctor ordered. Review of the evidence of the impact of computerized physician order entry system on medication errors. Health Serv Res 2008, 43(1 Pt 1):32-53.

43. Eslami S, Abu-Hanna A, De Keizer NF, De Jonge E: Errors associated with applying decision support by suggesting default doses for aminoglycosides. Drug Safety 2006, 29:803-809.

44. Williams CK, Maddox RR: Implementation of an i.v. medication safety system. Am J Health Syst Pharm 2005, 62:530-536.

45. Cummings J, Bush P, Smith D, Matuszewski K: Bar-coding medication administration overview and consensus recommendations. Am J Health Syst Pharm 2005, 62:2626-2629.

46. Pronovost $P$, Weast $B$, Schwarz $M$, Wyskiel RM, Prow $D$ Milanovich SN, Berenholtz S, Dorman T, Lipsett P: Medication reconciliation: a practical tool to reduce the risk of medication errors. J Crit Care 2003, 18:201-205.

47. Sittig DF, Stead WW: Computer-based physician order entry: the state of the art. J Am Med Inform Assoc 1994, 1:108-123.

48. Weant KA, Cook AM, Armitstead JA: Medication-error reporting and pharmacy resident experience during implementation of computerized prescriber order entry. Am J Health Syst Pharm 2007, 64:526-530.

49. Eslami S, Keizer NF, Abu-Hanna A: The impact of computerized physician medication order entry in hospitalized patients-A systematic review. Int J Med Inform 2007, Nov 17 [Epub ahead of print].

50. Ash JS, Gorman PN, Seshadri V, Hersh WR: Computerized physician order entry in U.S. hospitals: results of a 2002 survey. J Am Med Inform Assoc 2004, 11:95-99.

51. Bell CM, Rahimi-Darabad P, Orner Al: Discontinuity of chronic medications in patients discharged from the intensive care unit. J Gen Intern Med 2006, 21:937-941.

52. Stampi C: Ultrashort sleep/wake patterns and sustained performance. In Sleep and Alertness: Chronobiological, Behavioral, and Medical Aspects of Napping. Edited by Dinges DF B, Broughton RJ. New York: Raven Press; 1989:456.

53. Landrigan CP, Rothschild JM, Cronin JW, Kaushal R, Burdick E, Katz JT, Lilly CM, Stone PH, Lockley SW, Bates DW, Czeisler CA: Effect of reducing interns' work hours on serious medical errors in intensive care units. N Engl J Med 2004, 351:18381848.

54. Drazen JM: Awake and informed. $N$ Engl J Med 2004, 351: 1884. 
55. Lesar TS, Briceland LL, Delcoure K, Parmalee JC, Masta-Gornic $\mathrm{V}, \mathrm{Pohl} \mathrm{H}$ : Medication prescribing errors in a teaching hospital. JAMA 1990, 263:2329-2334.

56. LaPointe NM, Jollis JG: Medication errors in hospitalized cardiovascular patients. Arch Intern Med 2003, 163:1461-1466.

57. Wasserfallen JB, Butschi AJ, Muff P, Biollaz J, Schaller MD, Pannatier A, Revelly JP, Chiolero R: Format of medical order sheet improves security of antibiotics prescription: The experience of an intensive care unit. Crit Care Med 2004, 32:655-659.

58. Van Den Bemt PMLA, Fijn R, Van Der Voort PHJ, Gossen AA, Egberts TCG, Brouwers JRBJ: Frequency and determinants of drug administration errors in the intensive care unit. Crit Care Med 2002, 30:846-850.

59. Pronovost PJ, Angus DC, Dorman T, Robinson KA, Dremsizov TT, Young TL: Physician staffing patterns and clinical outcomes in critically ill patients: a systematic review. JAMA 2002, 288: 2151-2162.

60. Durbin CG Jr.: Team model: advocating for the optimal method of care delivery in the intensive care unit. Crit Care Med 2006, 34(3 Suppl):S12-17.

61. Leape LL, Brennan TA, Laird N, Lawthers AG, Localio AR, Barnes BA, Hebert L, Newhouse JP, Weiler PC, Hiatt H: The nature of adverse events in hospitalized patients. Results of the Harvard Medical Practice Study II. N Engl J Med 1991, 324: 377-384.

62. Bjornson DC, Hiner WO Jr., Potyk RP, Nelson BA, Lombardo FA, Morton TA, Larson LV, Martin BP, Sikora RG, Cammarata FA: Effect of pharmacists on health care outcomes in hospitalized patients. Am J Hosp Pharm 1993, 50:1875-1884.

63. Boyko WL Jr., Yurkowski PJ, Ivey MF, Armitstead JA, Roberts BL: Pharmacist influence on economic and morbidity outcomes in a tertiary care teaching hospital. Am J Health Syst Pharm 1997, 54:1591-1595.

64. Bond CA, Raehl CL: Clinical pharmacy services, pharmacy staffing, and hospital mortality rates. Pharmacotherapy 2007, 27:481-493.

65. Montazeri M, Cook DJ: Impact of a clinical pharmacist in a multidisciplinary intensive care unit. Crit Care Med 1994, 22:10441048.

66. Baldinger SL, Chow MS, Gannon RH, Kelly ET 3rd: Cost savings from having a clinical pharmacist work part-time in a medical intensive care unit. Am J Health Syst Pharm 1997, 54:28112814.

67. Beckmann U, Baldwin I, Durie M, Morrison A, Shaw L: Problems associated with nursing staff shortage: an analysis of the first 3600 incident reports submitted to the Australian Incident Monitoring Study (AIMS-ICU). Anaesth Intensive Care 1998, 26:396-400.

68. Whitman GR, Kim Y, Davidson LJ, Wolf GA, Wang SL: The impact of staffing on patient outcomes across specialty units. J Nurs Adm 2002, 32:633-639.

69. Pronovost $\mathrm{P}, \mathrm{Wu} \mathrm{AW}, \mathrm{Dorman} \mathrm{T}$, Morlock L: Building safety into ICU care. J Crit Care 2002, 17:78-85.

70. Hanneman SK: Advancing nursing practice with a unit-based clinical expert. Image J Nurs Sch 1996, 28:331-337.

71. Reason J: Human error: models and management. BMJ 2000, 320:768-770.

72. Al-Ansari MA, Hijazi MH: Medical errors and adverse events: focus on the intensive care unit. Clinical Intensive Care 2006, 17:9-17.

73. Bion JF, Heffner JE: Challenges in the care of the acutely ill. Lancet 2004, 363:970-977.

74. Crane VS: New perspectives on preventing medication errors and adverse drug events. Am J Health Syst Pharm 2000, 57: 690-697.

75. Barach $P$, Small SD: Reporting and preventing medical mishaps: lessons from non-medical near miss reporting systems. BMJ 2000, 320:759-763.

76. Stelfox HT, Bates DW, Redelmeier DA: Safety of patients isolated for infection control. JAMA 2003, 290:1899-1905.

77. ASHP guidelines on preventing medication errors in hospitals. Am J Hosp Pharm 1993, 50:305-314.

78. Weingart SN, Wilson RM, Gibberd RW, Harrison B: Epidemiology of medical error. BMJ 2000, 320:774-777.

79. Herout PM, Erstad BL: Medication errors involving continuously infused medications in a surgical intensive care unit. Crit Care Med 2004, 32:428-432.
80. Stambouly JJ, McLaughlin LL, Mandel FS, Boxer RA: Complications of care in a pediatric intensive care unit: a prospective study. Intensive Care Med 1996, 22:1098-1104.

81. Donchin $\mathrm{Y}$, Seagull FJ: The hostile environment of the intensive care unit. Curr Opin Crit Care 2002, 8:316-320.

82. Pronovost PJ, Jenckes MW, Dorman T, Garrett E, Breslow MJ, Rosenfeld BA, Lipsett PA, Bass E: Organizational characteristics of intensive care units related to outcomes of abdominal aortic surgery. JAMA 1999, 281:1310-1317.

83. Bria WF 2nd, Shabot MM: The electronic medical record, safety, and critical care. Crit Care Clin 2005, 21:55-79, viii.

84. Brennan TA, Leape LL, Laird NM, Hebert L, Localio AR, Lawthers AG, Newhouse JP, Weiler PC, Hiatt HH: Incidence of adverse events and negligence in hospitalized patients. Results of the Harvard Medical Practice Study I. N Engl J Med 1991, 324: 370-376. 